\title{
DEVELOPMENT AND VALIDATION OF NOVEL REVERSE-PHASE HIGH-PERFORMANCE LIQUID CHROMATOGRAPHY METHOD FOR SIMULTANEOUS ESTIMATION OF ANDROGRAPHOLIDE AND ALOE-EMODIN
}

\author{
RASHMI PATIL, UTTARA JAISWAR, VANDANA JAIN* \\ Department of Quality Assurance, Oriental College of Pharmacy, Sanpada, Navi Mumbai, Maharashtra, India. \\ Email: vandana.jain@ocp.edu.in
}

Received: 22 October 2019, Revised and Accepted: 19 December 2019

\begin{abstract}
Objective: The study aims to develop and validate a novel reverse-phase high-performance liquid chromatographic method for simultaneous estimation of andrographolide and aloe-emodin in herbal formulation and validate as per the International Conference on Harmonization (ICH) guidelines.
\end{abstract}

Methods: The analysis was carried on a Shimadzu LC Prominence-i 2030 model with the Lab Solution software. The column used for separation was Prontosil C18 $(250 \times 4.6 \mathrm{~mm}, 5 \mu)$, with a mobile phase consisting of acetonitrile and $0.05 \%$ orthophosphoric acid (45:55), at a flow rate of $1 \mathrm{ml} / \mathrm{min}$, column temperature was maintained at $28^{\circ} \mathrm{C}$ and effluents were monitored at $225 \mathrm{~nm}$. The injection volume was $10 \mu \mathrm{l}$.

Results: The retention time of andrographolide and aloe-emodin was found to be $4.57 \pm 0.2$ min and $12.29 \pm 0.2$ min, respectively. The markers were resolved using linear responses that were obtained in concentration ranges of $0.5-60 \mu \mathrm{g} / \mathrm{ml}$ with correlation coefficient $\left(\mathrm{r}^{2}\right)$ of 0.9992 and 0.999 for andrographolide and aloe-emodin, respectively. The precision results were found to be satisfactory, which indicates that the method is precise. The recovery values lie in the range of $98-120 \%$ indicating the accuracy of the method.

Conclusion: A novel, simple, accurate, precise, and robust reverse-phase high-performance liquid chromatography method was developed for the simultaneous estimation of andrographolide and aloe-emodin. The developed method can be used for analysis of the formulations containing these phytoconstituents.

Keywords: Andrographolide, Aloe-emodin, Marketed formulation, International Conference on Harmonization guidelines.

(c) 2020 The Authors. Published by Innovare Academic Sciences Pvt Ltd. This is an open access article under the CC BY license (http://creativecommons. org/licenses/by/4. 0/) DOI: http://dx.doi.org/10.22159/ajpcr.2020.v13i2.36158

\section{INTRODUCTION}

Ayurvedic medicines are polyherbal formulations and every herb consists of an array of chemical constituents.

Plants are considered as a conventional source for a large number of phytochemicals [1]. Ayurvedic medicines are polyherbal formulations and each herb consists of various chemical constituents [2]. The quality assessment of herbal formulations is vital to justify their acceptability in the modern system of medicine. The production and primary processing of herbal substance influences the quality of the active pharmaceutical ingredient [3]. Standardization of polyherbal formulations and the quantitative determination of markers in any polyherbal formulation is very challenging [4]. Standardization of herbal products can be achieved if they are evaluated using sophisticated techniques such as ultraviolet (UV)-visible, infrared, thin-layer chromatography, highperformance liquid chromatography (HPLC), high-performance thinlayer chromatography, gas chromatography-mass spectrometry, liquid chromatography-mass spectrometer, atomic absorption spectrometry spectrofluorimetric, and other such methods [5]. The literature survey reveals that various methods were developed for estimation of andrographolide and aloe-emodin alone or in combination with other markers [6-12], but no such HPLC analysis method for simultaneous estimation of andrographolide and aloe-emodin is reported

This paper presents the development of a novel reverse-phase HPLC (RP-HPLC) method for the simultaneous estimation of andrographolide and aloe-emodin. The developed and validated method was applied for the standardization of marketed formulation for these two markers. The selected formulation is a well-known formulation and is indicated against various complications such as jaundice, liver disorder, indigestion, hepatotoxicity, liver enlargement, gastroenteritis, fungal infections, gastritis, and other conditions [13]. This tablet consists of various medicinal plants namely, Bhringaraj (Eclipta alba), Revandchini (Rheum emodi), Sarapunkha (Tephrosia purpurea), Kalmegh (Andrographis paniculata), Kasni (Cichorium intybus), Giloy (Tinospora cordifolia), Hareetaki (Terminalia chebula), and Bhumyamlaki (Phyllanthus niruri). Andrographolide from A. paniculata is reported to possess abortifacient, anti-inflammatory, antibacterial, antipyretic, antithrombotic, antiviral, antineoplastic, cardioprotective, choleretic, digestive, expectorant, hepatoprotective, hypoglycemic, immune enhancement, laxative, and sedative activity [14]. Andrographolide is effective against liver damage caused by paracetamol or galactosamine. It also played a hepatoprotective role by reducing a lipid peroxidation product malondialdehyde [15]. aloe-emodin from $R$. emodi possess antioxidant, antimicrobial, antifungal, anticancer, antiulcer, antidyslipidemic, hepatoprotective, wound healing, and immune-enhancing activity [16]. Aloe-emodin also possesses multiple antiproliferative and anticarcinogenic properties in a host of cancer cell lines [17].

\section{METHODS}

Instrument

RP-HPLC Shimadzu LC Prominence-i 2030 model consisting of UV detector and autosampler was employed for the method development and validation. Software used was Lab Solution. UV-visible spectrophotometer was used for obtaining maximum wavelength $(\lambda \max )$ of the compounds of interest. 
Standards and reagents

Andrographolide and aloe-emodin standards were obtained from Yucca Enterprises, Mumbai, Maharashtra, India. Marketed formulation of Livfit Tablet of Alembic Pharmaceuticals Ltd. was procured from the local market of Mumbai, Maharashtra, India. All the chemicals used were of HPLC grade, which were procured from Thermo Fisher Scientific, India Pvt. Ltd., Powai, Mumbai.

\section{Chromatographic conditions}

HPLC (Shimadzu, Prominence-i 2030 model) with Lab Solution software was employed in this method. Prontosil C18 $(250 \times 4.6 \mathrm{~mm}, 5 \mu)$ column was used for analysis. The mobile phase used was acetonitrile: $0.05 \%$ orthophosphoric acid (45:55), at the flow rate of $1.0 \mathrm{ml} / \mathrm{min}$ and the injection volume was kept $10 \mu \mathrm{l}$. The column temperature was set at $28^{\circ} \mathrm{C}$. Andrographolide and aloe-emodin were detected at $225 \mathrm{~nm}$ using a UV detector.

\section{Selection of wavelength}

Standard solutions of andrographolide and aloe-emodin were prepared and scanned by a UV spectrophotometer. The range of detection was kept from 200 to $400 \mathrm{~nm}$ and the overlay spectra of andrographolide and aloe-emodin obtained are shown in Fig. $1.225 \mathrm{~nm}$ was selected as the detection wavelength for the analysis of andrographolide and aloeemodin as both the markers showed appreciable absorption at $225 \mathrm{~nm}$.

\section{Preparation of standard solutions}

Hundred mg of each marker (andrographolide and aloe-emodin) was transferred individually in two volumetric flasks of $100 \mathrm{ml}$ and the volume was made up with methanol to obtain solutions of $1000 \mu \mathrm{g} / \mathrm{ml}$. These were used as stock solutions and were used after suitable dilutions.

\section{Preparation of working solutions}

Working solutions were prepared from the standard solution of markers. A combined solution of markers having a concentration of $100 \mu \mathrm{g} / \mathrm{ml}$ was prepared from the stock solution. This was further diluted to get dilutions of $0.5,1,5,10,20,50$, and $60 \mu \mathrm{g} / \mathrm{ml}$ which were used to construct a calibration curve.

\section{Preparation of sample solution}

Ten tablets were triturated and about $2 \mathrm{~g}$ powder was weighed and was subjected to reflux using methanol as extracting solvent. Triturated powder was transferred into the $100 \mathrm{ml}$ round bottom flask and $100 \mathrm{ml}$ methanol was added to it and was placed in a heating mantle and extraction was continued for $20 \mathrm{~min}$. The solution was further filtered using the Whatman Filter Paper to get a clear solution and the volume was made up to $100 \mathrm{ml}$ using methanol. This solution was sonicated before injection

\section{RESULTS AND DISCUSSION}

\section{Method development}

A series of trials was carried out using various mobile phases such as acetonitrile: Phosphate buffer (60:40) having different $\mathrm{pH}$, acetonitrile: $0.1 \%$ orthophosphoric acid (50:50), acetonitrile: 0.05\% orthophosphoric acid (40:60) to develop RP-HPLC method for simultaneous estimation of andrographolide, and aloe-emodin in the marketed formulation. Finally, acetonitrile: $0.05 \%$ orthophosphoric acid (45:55) was selected as the mobile phase based on better peak resolution and peak symmetry. Prontosil C18 column $(250 \times 4.6 \mathrm{~mm}$, $5 \mu$ ) was used for analysis and injection volume was kept $10 \mu$ l. The flow rate was $1.0 \mathrm{ml} / \mathrm{min}$ and the run time was $15 \mathrm{~min}$. The column temperature was set at $28^{\circ} \mathrm{C}$ and the detection was carried out at $225 \mathrm{~nm}$. The retention time (RT) of andrographolide and aloe-emodin obtained was found to be $4.57 \pm 0.2 \mathrm{~min}$ and $12.29 \pm 0.2 \mathrm{~min}$, respectively. Chromatograms of standard and sample of andrographolide and aloeemodin are shown in Figs. 2 and 3. The optimized chromatographic conditions are tabulated in Table 1.

\section{Method validation}

The developed method was validated for parameters such as linearity, specificity, precision, accuracy, robustness, and solution stability as per the International Conference on Harmonization (ICH) guidelines [18].

\section{Specificity}

It is performed to ensure the identification, purity testing, and quantification of marker compound from the ayurvedic formulation under analysis. Specificity was confirmed by comparing the RTs and UV spectra of the standards with the component obtained in chromatograms of the extract of tablets. The developed method was found to be specific as there was no interference of any other constituents at the RTs of both markers andrographolide and aloe-emodin as depicted in Figs. 2 and 3.

\section{Linearity}

Linearity was evaluated by analyzing the plot area as a function of the concentration of analyte. Andrographolide and aloe-emodin showed a linear response in the concentration range of $0.5-60 \mu \mathrm{g} / \mathrm{ml}$. The linearity was constructed by plotting peak area versus concentration of analyte. The linearity was validated by the high value of correlation coefficients $\left(\mathrm{r}^{2}\right) 0.9992$ and 0.999 for andrographolide and aloeemodin, respectively, which meets the acceptance criteria for method validation. The results are tabulated in Table 2 and plots obtained are given in Figs. 4 and 5.

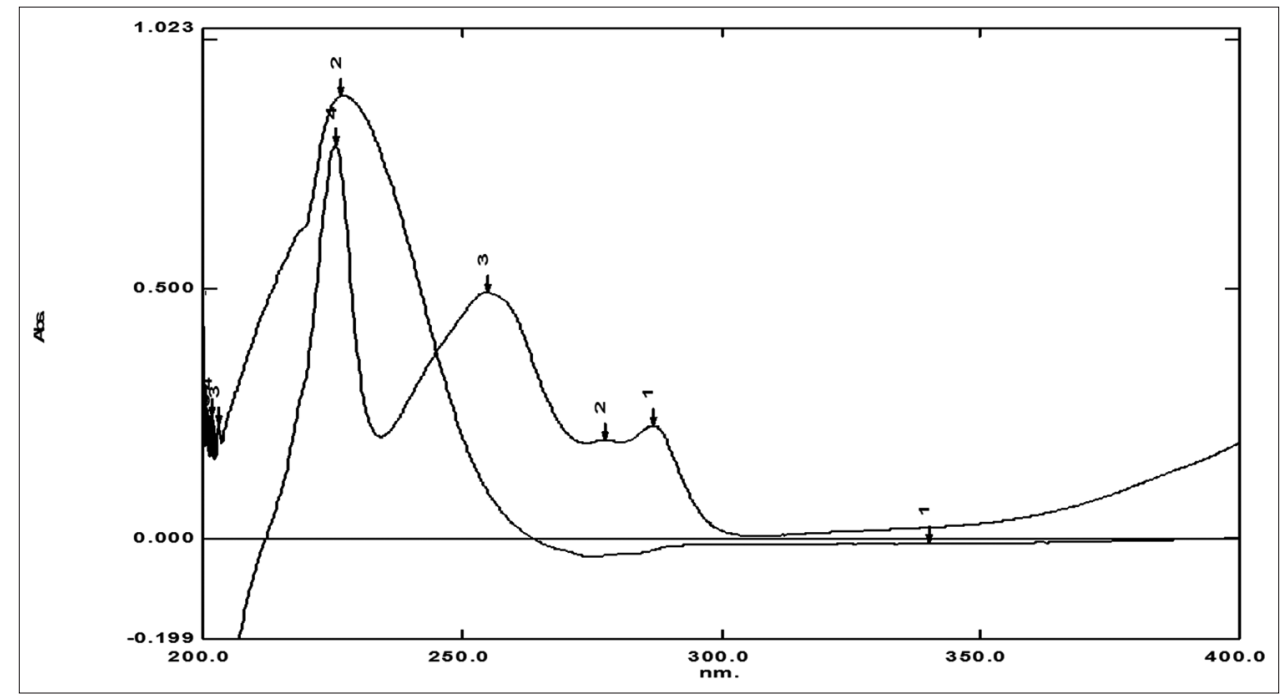

Fig. 1: Ultraviolet overlap spectrum of andrographolide and aloe-emodin 


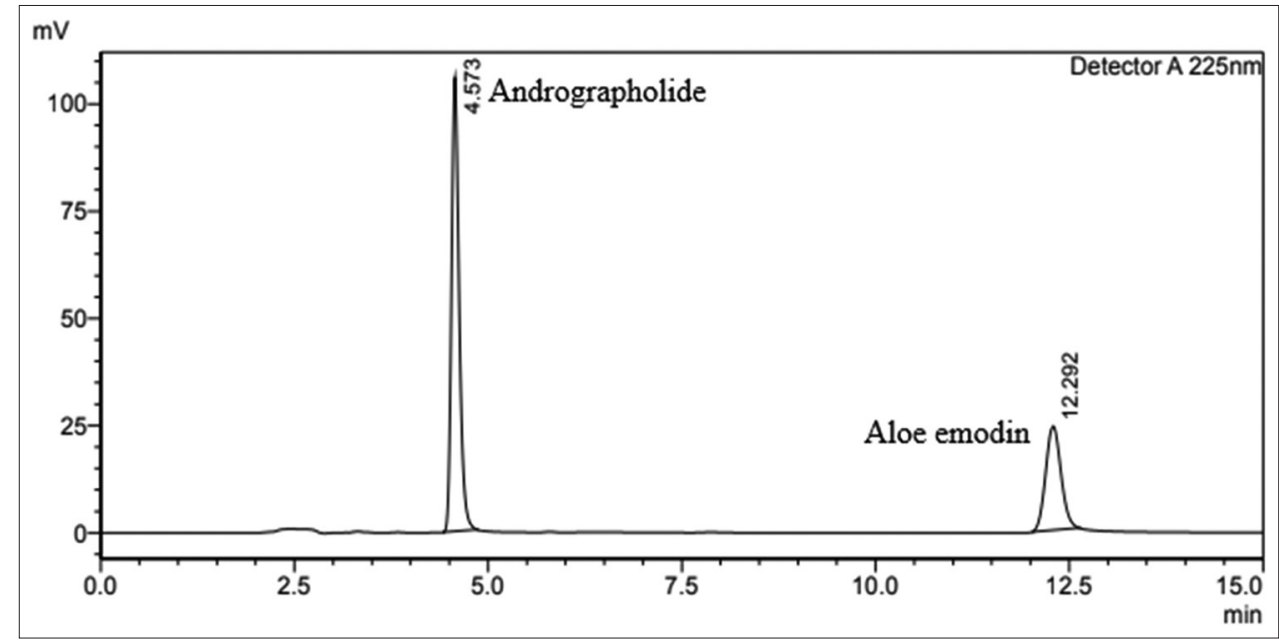

Fig. 2: High-performance liquid chromatography chromatogram of a standard mixture of andrographolide and aloe-emodin obtained using optimized conditions

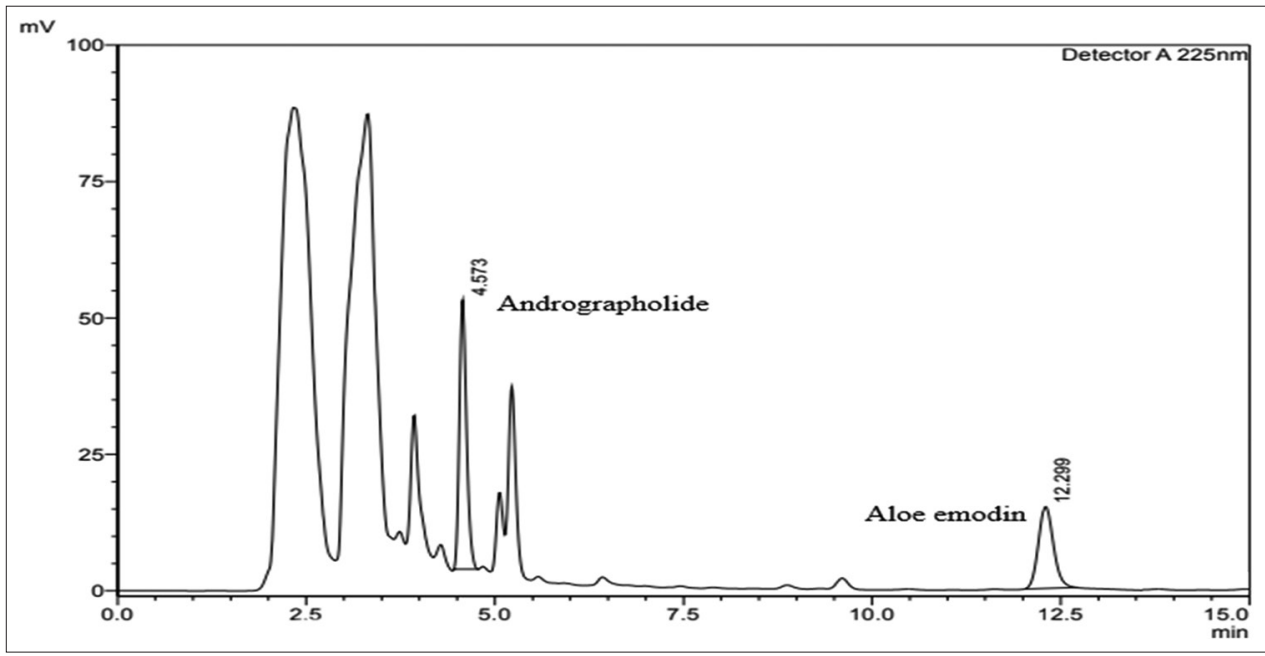

Fig. 3: Chromatogram of extract of marketed formulation

Table 1: Optimized chromatographic conditions for andrographolide and aloe-emodin

\begin{tabular}{ll}
\hline Parameters & Optimized conditions \\
\hline Column & Prontosil C18, $(250 \times 4.6 \mathrm{~mm}, 5 \mu)$ \\
Mobile phase & Acetonitrile: $0.05 \%$ orthophosphoric acid \\
& $(45: 55)$ \\
Detector & UV detector \\
Detection wavelength & $225 \mathrm{~nm}$ \\
Column temperature & $28^{\circ} \mathrm{C}$ \\
Injection volume & $10 \mu \mathrm{l}$ \\
Flowrate & $11.0 \mathrm{ml} / \mathrm{min}$ \\
Run time & $15 \mathrm{~min}$ \\
Retention time & 4.57 and $12.29 \mathrm{~min}$ \\
\hline UV: Ultraviolet &
\end{tabular}

\section{Limit of detection (LOD)}

The LOD of an individual analytical method is the lowest amount of analyte in a sample which can be detected but not necessarily quantified as an exact value. The LOD is expressed as LOD $=3.3 \mathrm{\sigma} / \mathrm{S}$, where $\sigma=$ standard deviation of intercepts of the calibration curve and $S$ is the Slope of the calibration curve.

Limit of quantification (LOQ)

LOQ is a parameter of quantitative assays for low levels of compounds (markers) in extracts. The $\mathrm{LOQ}$ is expressed as $\mathrm{LOQ}=10 \mathrm{\sigma} / \mathrm{S}$.
LOD and LOQ of andrographolide were found to be 0.14 and $0.44 \mu \mathrm{g} / \mathrm{ml}$, respectively, and that of aloe-emodin was found to be 0.13 and $0.40 \mu \mathrm{g} / \mathrm{ml}$, respectively. A low LOD and LOQ value indicates that the method is sensitive.

\section{Quantification of markers}

The amount of andrographolide and aloe-emodin present in the formulation was calculated using linear regression analysis. Quantification of the markers was done by performing HPLC analysis of test solutions. The area obtained for each of the markers from formulation was extrapolated on the calibration curve of the respective marker. The results are shown in Table 3.

\section{Precision}

The system precision was carried out by injecting six injections of standards of andrographolide and aloe-emodin and method precision was performed by injecting a sample of the same concentration 6 times. The percent relative standard deviation (\%RSD) was calculated from the area obtained from the chromatogram. The standard analysis of the results proved that \%RSD of the peak areas obtained was $<2 \%$; hence, the developed method was found to be precise. The data of precision are tabulated in Tables 4 and 5 .

\section{Accuracy (recovery)}

Recovery of andrographolide and aloe-emodin from formulation was checked by spiking a known quantity of standards at three concentration 


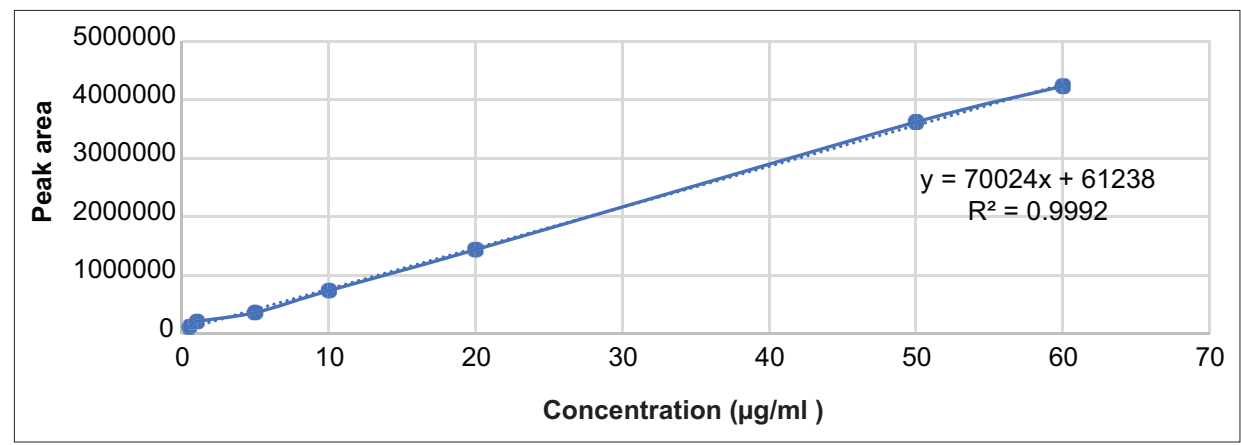

Fig. 4: Calibration curve of andrographolide

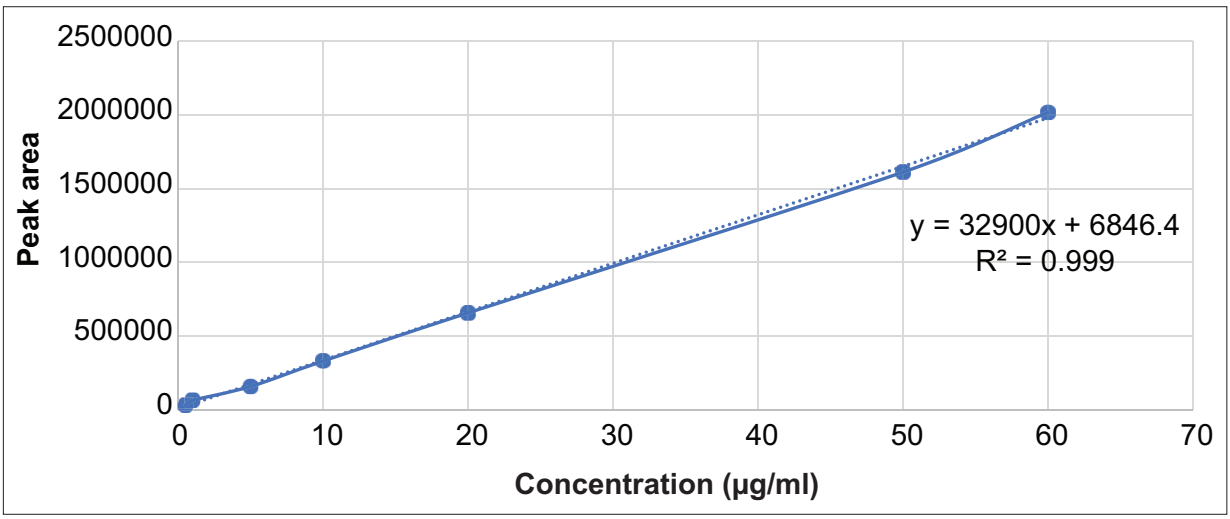

Fig. 5: Calibration curve of aloe-emodin

Table 2: Linear regression data obtained from calibration curves of andrographolide and aloe-emodin

\begin{tabular}{|c|c|c|c|}
\hline \multicolumn{2}{|c|}{ Concentration $(\mu \mathrm{g} / \mathrm{ml})$} & \multicolumn{2}{|l|}{ Area } \\
\hline Andrographolide & Aloe-emodin & Andrographolide & Aloe-emodin \\
\hline 0.5 & 0.5 & 109,805 & 30,416 \\
\hline 1 & 1 & 202,898 & 62,888 \\
\hline 5 & 5 & 357,499 & 157,427 \\
\hline 10 & 10 & 731,227 & 329,612 \\
\hline 20 & 20 & $1,433,500$ & 656,922 \\
\hline 50 & 50 & $3,619,588$ & $1,612,455$ \\
\hline 60 & 60 & $4,232,730$ & $2,018,109$ \\
\hline Slope & Slope & 70,024 & 32,900 \\
\hline Intercept & Intercept & 61,238 & 68,464 \\
\hline Correlation & Correlation & 0.9992 & 0.999 \\
\hline
\end{tabular}

Table 3: Analysis of markers in formulation

\begin{tabular}{ll}
\hline Markers & \%w/w content \\
\hline Andrographolide & 0.0023 \\
Aloe-emodin & 0.0115 \\
\hline
\end{tabular}

Table 4: System precision results

\begin{tabular}{|c|c|c|}
\hline \multirow[t]{2}{*}{ S. no. } & $\begin{array}{l}\text { Andrographolide } \\
(10 \mu \mathrm{g} / \mathrm{ml})\end{array}$ & $\begin{array}{l}\text { Aloe-emodin } \\
(20 \mu \mathrm{g} / \mathrm{ml})\end{array}$ \\
\hline & Peak area & Peak area \\
\hline 1. & 741,227 & 656,922 \\
\hline 2. & 741,708 & 654,925 \\
\hline 3. & 744,624 & 649,835 \\
\hline 4. & 749,309 & 653,309 \\
\hline 5. & 741,889 & 652,233 \\
\hline 6. & 741,264 & 652,590 \\
\hline Mean \pm SD & $743,337 \pm 3188$ & $653,302 \pm 2425$ \\
\hline$\%$ RSD & 0.43 & 0.37 \\
\hline
\end{tabular}

\%RSD: Percentage relative standard deviation, SD: Standard deviation
Table 5: Method precision results

\begin{tabular}{lll}
\hline S. no. & Andrographolide & Aloe-emodin \\
\cline { 2 - 2 } & Peak area & Peak area \\
\hline 1. & 125,903 & 158,946 \\
2. & 124,982 & 157,982 \\
3. & 125,467 & 158,268 \\
4. & 125,948 & 158,923 \\
5. & 125,120 & 157,689 \\
6. & 123,832 & 159,893 \\
Mean \pm SD & $125,209 \pm 781$ & $158,617 \pm 802$ \\
$\%$ RSD & 0.62 & 0.51 \\
\hline \%RSD: Percentage relative standard deviation, SD: Standard deviation
\end{tabular}

levels (i.e., $80 \%, 100 \%$, and $120 \%$ of the quantified amount) to the test samples in triplicate using HPLC. This way, accuracy was performed and calculated for nine determinations over a specified range and mean recovery was calculated. The acceptance limit for percent recovery ranges from 98 to $102 \%$. The mean \% recovery was found to be within the range, which indicates that the method is accurate. The percentage of recovery results is tabulated in Tables 6 and 7. 
Table 6: \% recovery results for andrographolide

\begin{tabular}{lllllll}
\hline Level $(\%)$ & Sample $(\boldsymbol{\mu g} / \mathbf{m l})$ & Standard added $(\boldsymbol{\mu g} / \mathbf{m l})$ & Total amount & Area $(\mathbf{n}=\mathbf{3}) *$ & Recovery & \% recovery \\
\hline 80 & 4.62 & 3.69 & 8.31 & 637535 & 8.23 & 99 \\
100 & 4.62 & 4.62 & 9.24 & 697055 & 9.08 & 98.26 \\
120 & 4.62 & 5.54 & 10.16 & 769880 & 10.12 & 99.6 \\
\hline
\end{tabular}

${ }^{*}$ n: number of injections

Table 7: \% recovery results for aloe-emodin

\begin{tabular}{|c|c|c|c|c|c|c|}
\hline Level (\%) & Sample $(\mu \mathrm{g} / \mathrm{ml})$ & Standard added $(\mu \mathrm{g} / \mathrm{ml})$ & Total amount & Area $(n=3)$ & Recovery & $\%$ recovery \\
\hline 80 & 23.1 & 18.48 & 41.58 & 1370880 & 41.46 & 99.71 \\
\hline 100 & 23.1 & 23.1 & 46.2 & 1519588 & 45.98 & 99.52 \\
\hline 120 & 23.1 & 27.72 & 50.82 & 1681127 & 50.89 & 100.1 \\
\hline
\end{tabular}

Table 8: Robustness results of andrographolide and aloe-emodin

\begin{tabular}{lllllll}
\hline \multirow{2}{*}{ Parameter } & \multirow{2}{*}{ Deviation } & \multicolumn{2}{l}{ \%RSD } & & \\
\cline { 3 - 4 } & & & \multicolumn{2}{l}{ Andrographolide } & & \multicolumn{2}{l}{ Aloe-emodin } \\
\cline { 3 - 4 } \cline { 6 - 7 } & & Area & RT & & Area & RT \\
\hline Flow rate & $0.8 \mathrm{ml}$ & 0.45 & 0.37 & & 0.41 & 0.46 \\
(ml/min) & $1.2 \mathrm{ml}$ & 0.92 & 1.23 & & 0.78 & 0.65 \\
Column & $27^{\circ} \mathrm{C}$ & 0.48 & 0.26 & & 0.60 & 0.38 \\
temperature & $29^{\circ} \mathrm{C}$ & 0.87 & 0.40 & & 0.35 & 0.21 \\
Wavelength & $224 \mathrm{~nm}$ & 0.32 & 0.48 & & 0.95 & 0.33 \\
& $226 \mathrm{~nm}$ & 0.58 & 0.29 & & 0.98 & 0.17 \\
\hline
\end{tabular}

RT: Retention time, \%RSD: Percentage relative standard deviation

Table 9: Solution stability of andrographolide and aloe-emodin

\begin{tabular}{lll}
\hline \multirow{2}{*}{ Time } & \%RSD & \\
\cline { 2 - 3 } & Andrographolide $(\mathbf{2 0} \boldsymbol{\mu g} / \mathbf{m l})$ & Aloe-emodin $(\mathbf{2 0} \boldsymbol{\mu g} / \mathbf{m l})$ \\
\hline Initial & 0.40 & 0.52 \\
$6 \mathrm{~h}$ & 0.37 & 0.66 \\
$12 \mathrm{~h}$ & 0.44 & 0.71 \\
$24 \mathrm{~h}$ & 0.50 & 0.82 \\
\hline
\end{tabular}

\%RSD: Percentage relative standard deviation

\section{Robustness}

Robustness of the analytical method was evaluated by making deliberate changes in the chromatographic conditions such as flow rate of mobile phase $( \pm 0.2 \mathrm{ml} / \mathrm{min})$, wavelength $( \pm 1 \mathrm{~nm})$, and column temperature $\left( \pm 1^{\circ} \mathrm{C}\right)$. Each marker was analyzed in triplicate in order. The $\%$ RSD was found to be within limits this ensured that the method is robust. The results of robustness are shown in Table 8.

\section{Solution stability}

The solution of andrographolide and aloe-emodin was injected at different time intervals for evaluating the stability of the solution. The \%RSD was calculated. The solution stability of 24 h showed that the solution can be used over $24 \mathrm{~h}$ without any degradation. The results are depicted in Table 9.

\section{CONCLUSION}

A novel HPLC method was developed and validated for the simultaneous estimation of andrographolide and aloe-emodin. This method was validated according to the ICH Q2 (R1) guidelines in the terms of linearity, precision, LOD, LOQ accuracy, and robustness. The developed method is simple, linear, robust, precise, and accurate for the determination of andrographolide and aloe-emodin and can be used for the analysis of both the markers in the formulation. Peaks of both the markers were sharp and well resolved. Both the markers were quantified from formulation under study. Hence, the proposed method can be applied for routine qualitative and quantitative analysis of andrographolide and aloe-emodin in an ayurvedic formulation containing these phytoconstituents.

\section{ACKNOWLEDGMENT}

The authors are thankful to the Oriental College of Pharmacy for providing necessary facilities for research.

\section{AUTHORS' CONTRIBUTIONS}

All the authors have contributed equally in performing analysis and writing the manuscript.

\section{CONFLICTS OF INTEREST}

The authors declare that there are no conflicts of interest in this research work.

\section{AUTHORS' FUNDING}

The authors are thankful to Oriental College of Pharmacy for funding the project.

\section{REFERENCES}

1. Arunachalam KD, Kuruva JK, Hari S, Annamalai SK, Baskaran KV. HPTLC finger print analysis and phytochemical investigation of Morinda tinctoria roxb leaf extracts by HPLC and GC MS. Int J Pharm Pharm Sci 2015;7:360-6

2. Shaikh H, Jain V. A novel, simple, rapid RP-HPLC method for simultaneous estimation of ferulic acid, quercetin, piperine and thymol in Ayuvedic formulation. Int J Appl Pharm 2018;10:303-8.

3. EMEA. Quality of Herbal Medicinal Products. Guidelines. European Agency for the Evaluation of Medicinal Products (EMEA): London; 1998.

4. Ong ES. Extraction methods and chemical standardization of botanicals and herbal preparations. J Chromatogr B Analyt Technol Biomed Life Sci 2004:812:23-33.

5. Lokhande S, Chougule A, Patil S, Patil V. Need of herbal drug standardization. Int Ayurvedic Med J 2015;3:874-7.

6. Kotagiri R, Kanaujia A, Singh P, Thakur D. Validated RP-HPLC method for the quantification of andrographolide in toxiroak premix, a polyherbal mycotoxin inhibitor. Int J Pharm Sci Res 2013;4:2623-8.

7. Xu W, Yang W. Assay of andrographolide bulk drug by HPLC. Zhongguo Zhong Yao Za Zhi 2010;35:2113-5.

8. Bhope SG, Kuber VV, Nagore DH, Gaikwad PS, Patil MJ. Development and validation of RP-HPLC method for simultaneous analysis of andrographolide, phyllanthin and hypophyllanthin from herbal hepatoprotective formulation. Acta Chromatogr 2013;25:159-69.

9. Kumaran KS, Thirugnanasambantham P, Vishwanathan S, murthy MS. An HPLC method for the estimation of andrographolide in rabbit serum. Indian J Pharmacol 2003;35:109-12.

10. Mandrioli R, Mercolini L, Ferranti A, Fanali S, Raggi MA. Determination of aloe emodin in Aloe vera extracts and commercial formulations by HPLC with tandem UV absorption and fluorescence detection. Food Chem 2011;126:387-93.

11. Tabin S, Gupta RC, Bansal G, Kamili AN. Comparative HPLC analysis 
of emodin, aloe emodin and rhein in Rheum emodi of wild and in vitro raised plants. J Pharmacogn Phytochem 2016;5:121-30.

12. Zaffaroni M, Mucignat C, Pecera T, Zagotto G, Frapolli R, D'Iucalci M, et al. High-performance liquid chromatographic assay for the determination of aloe emodin in mouse plasma. J Chromatogr B Analyt Technol Biomed Life Sci 2003;796:113-9.

13. New Livfit Tablet Uses, Side effects, Reviews, and Precautions Alembic Pharma Tablet Wise India. Available from: https://www.tabletwise. com/new-livfit-tablet. [Last accessed on 2019 Sep 18].

14. Joseph J, Solomon J. Andrographis paniculata: A review of its traditional uses, phytochemistry and pharmacology. Med Aromat Plants 2014;3:2-14.
15. Handa SS, Sharma A. Hepatoprotective activity of andrographolide against galactosamine and paracetamol intoxication in rats. Indian $\mathrm{J}$ Med Res 1990;92:284-92.

16. Malik MA, Bhat SA, Bilquees F, Sheikh BA, Sidiqui S, Shrivastava P. Rheum emodi as valuable medicinal plant. Int J Gen Med Pharm 2016;5:35-44

17. Sanders B, Ray AM, Goldberg S, Clark T, Clark T, McDaniel HR, et al. Anti-cancer effects of aloe-emodin: A systematic review. J Clin Transl Res 2017;3:283-96.

18. ICH Harmonised, Tripartite Guideline Validation of Analytical Procedures: Text and Methodology Q2(R1), Geneva; 2005. p. 1-13. 